\title{
Macrophage infiltration in the omental and subcutaneous adipose tissues of dairy cows with displaced abomasum
}

\author{
G. Andres Contreras, ${ }^{* 1}$ Ed Kabara, ${ }^{*}$ Jill Brester, ${ }^{*}$ Louis Neuder, ${ }^{*}$ and Matti Kiupel† \\ *Department of Large Animal Clinical Sciences, and \\ †Department of Pathobiology and Diagnostic Investigation, College of Veterinary Medicine, Michigan State University, East Lansing 48824
}

\begin{abstract}
High concentrations of plasma nonesterified fatty acids (NEFA), a direct measure of lipolysis, are considered a risk factor for displaced abomasum (DA) and other clinical diseases. In nonruminants, uncontrolled lipolysis is commonly associated with adipose tissue macrophage (ATM) infiltration. In dairy cows, recent studies report ATM infiltration in specific adipose depots during the first week of lactation. Depending on their phenotype, ATM can be broadly classified as classically activated (M1) or alternatively activated (M2). The M1 ATM are considered pro-inflammatory, whereas M2 ATM enhance inflammation resolution. Currently, it is not known whether multiparous transition cows with DA have increased ATM infiltration, and the predominant phenotype of these mononuclear cells remains unclear. The objective of this study was to characterize ATM infiltration into different adipose tissue depots in transition cows with DA (days in milk $=7.8 \pm 4.6 \mathrm{~d}$; body condition score $=2.95 \pm 0.10 ; \mathrm{n}=6)$. Serum samples and biopsies from omental $(\mathrm{OM})$ and subcutaneous (SC) fat depots were obtained during corrective surgery for DA. In an effort to compare ATM infiltration in DA cows with that of healthy cows in anabolic state (AS), adipose biopsies and blood samples were collected from nonlactating, nongestating dairy cows at the time of slaughter (body condition score $=3.75 \pm 0.12 ; \mathrm{n}=6$ ) . Adipose tissues were digested and cells from the stromal vascular fraction (SVF) were analyzed using flow cytometry to establish cell surface expression of specific macrophage markers including CD14, CD11c, CD163, and CD172a. Tissue sections were analyzed by immunohistochemistry to assess ATM localization. Cows with DA were ketotic and had plasma NEFA above $1.0 \mathrm{mEq} / \mathrm{L}$. The same group of cows had significant infiltration of ATM in OM characterized by increased numbers of SVF cells expressing CD14 and CD172a. At the same time, expression of CD11c, and CD163
\end{abstract}

Received January 21, 2015.

Accepted May 11, 2015.

${ }^{1}$ Corresponding author: contre28@msu.edu was significantly higher in SVF from OM and SC of DA cows compared with those from AS animals. Expression of M1 macrophage inflammatory phenotyperelated genes CCL2, IL6, and TNF $\alpha$ in SVF from cows with DA was significantly higher than that in healthy cows (AS). Significant populations of ATM in OM and SC depots of cows with DA were localized in multiple cellular aggregates that included multinucleated cells. In contrast, ATM in AS cows were fewer and randomly localized in both SC and OM. Together, these results indicate that infiltration of classically activated ATM is a concurrent finding in DA cases and may be associated with metabolic stress around parturition contributing to the pro-inflammatory status of transition dairy cows. Future studies are needed to establish whether ATM infiltration is more pronounced in cows with DA compared with healthy dairy cows at the same lactation stage and if this increased mononuclear immune cell trafficking has any pathophysiological significance.

Key words: adipose tissue macrophage, nonesterified fatty acids, lipolysis, displaced abomasum

\section{INTRODUCTION}

Displaced abomasum (DA) is a clinical disease with high economic impact to the dairy industry. In the United States alone, annual losses were calculated to be $\$ 220$ million (Geishauser et al., 1996). Nearly $90 \%$ of DA cases are diagnosed during the transition period - 2 wk before until 4 wk after parturition - and between 12 and $65 \%$ of these cows die or are culled within $60 \mathrm{~d}$ after surgical correction (Shaver, 1997; Sterner et al., 2008; Boulay et al., 2014). Plasma NEFA concentrations $>0.72 \mathrm{mEq} / \mathrm{L}$ during the first week after parturition are considered a risk predictor for DA (Ospina et al., 2010; Seifi et al., 2011). These NEFA values are a reflection of high lipolysis rates within the adipose tissue of transition cows (Sumner and McNamara, 2007). However, the mechanisms by which lipolysis predisposes to DA are poorly understood. Recent advances in adipose tissue biology demonstrated that, during lipolysis, the adipose tissue undergoes a remodeling process characterized by dynamic changes in its cellular and structural composi- 
tion (Kosteli et al., 2010; Lee et al., 2014). In rodents, lipolysis induced an inflammatory response characterized by adipose tissue macrophage (ATM) infiltration that was followed by proliferation of preadipocytes and other cellular components of the stromal vascular fraction (SVF) of adipose tissues (Granneman et al., 2005; Kosteli et al., 2010). In dairy cows, recent reports indicated a similar process during the transition period, where elevated lipolysis rates coincided with enhanced adipose tissue inflammatory responses and ATM infiltration. Gene expression of the pro-inflammatory cytokines tumor necrosis factor $\alpha$ ( TNF $\mathbf{\alpha})$, IL1 $\beta$, and IL6, as well as important components of the nuclear factor $\kappa \mathrm{B}(\mathbf{N F} \boldsymbol{\kappa} \mathbf{B})$ pathway including IKBKE and TBK1, was upregulated during the first weeks of lactation in different fat depots (Schmitt et al., 2011; Saremi et al., 2014). In first-lactation dairy heifers, Akter et al. (2012) described an increased number of ATM in omental and mesenteric adipose depots $1 \mathrm{~d}$ after parturition. Nevertheless, adipose tissue inflammatory responses and ATM infiltration during intense lipolytic periods such as those observed in mature transition dairy cows with DA have not been evaluated.

Macrophages are the most abundant immune cell in adipose tissue of rodents and humans comprising $\sim 5 \%$ of the cell population and more than half of the leukocytes in fat depots (Ferrante, 2013). In these species, ATM populations are characterized by the expression of cluster of differentiation (CD) markers (e.g., CD14, CD11b, CD11c, CD68, CD163, and F4/80) using flow cytometry, immunohistology, and immunocytology applications (Curat et al., 2006; Cho et al., 2014). In dairy cattle, monocytes and macrophages are commonly identified by the expression of CD14, CD68, and CD172a. Marker CD14 is a high-affinity receptor for LPS and other bacterial wall components that are strongly expressed in bovine macrophages (Sopp et al., 1996). Marker CD172a is a transmembrane regulatory protein expressed in monocytes, macrophages, and dendritic cells that is essential for mononuclear cell trafficking (Palmer et al., 2009); CD68 is a lysosomal-associated membrane protein in bovine macrophages (Kitani et al., 2011). Both CD14 and CD172a are widely used in flow cytometry applications (Bastos et al., 2007; O'Boyle et al., 2012; Hussen et al., 2014), whereas CD68 and CD172a are reported in immunohistochemical assays (Ackermann et al., 1994; Kitani et al., 2011; Akter et al., 2012). Despite novel reports describing ATM infiltration in different adipose depots of first-lactation cows using immunohistochemistry (Akter et al., 2012), no studies have characterized ATM populations using flow cytometry in healthy or diseased dairy cows.

Upon migration to the adipose tissue, monocytes mature into resident macrophages that become activated during inflammatory processes. The cytokine milieu induced by the immune response directs activated macrophages to express specialized functional properties in a process known as polarization (Martinez et al., 2006). In rodents and humans, M1 polarization, or classical activation, induces macrophages to express pro-inflammatory cytokines and increases their microbicidal and tumoricidal activity. In contrast, M2 macrophages are considered alternatively activated and immuneregulatory, and they promote tissue remodeling and inflammation resolution (Sica and Mantovani, 2012). In rodents and humans, M1 macrophages are characterized by the expression of CD11c and pro-inflammatory cytokines including IL1 $\beta$, IL6, monocyte chemoattractant protein 1 (MCP-1, encoded by the gene $C C L 2)$ and TNFa (Lumeng et al., 2007). In contrast, M2 macrophages are CD11c negative, express arginase 1 (ARG1) and IL10, and co-express the surface markers CD163 and CD206 (Fujisaka et al., 2009; Chawla et al., 2011). Less is known about ATM inflammatory phenotypes in transition dairy cow with DA or during states of positive or negative energy balance (NEB). The objective of this study was to assess ATM infiltration in cows with DA and in healthy, nongestating dry cows and to evaluate their inflammatory phenotype. We report increased infiltration of ATM that were polarized to the M1 phenotype and formed aggregates in the omental and subcutaneous adipose depots of cows with DA.

\section{MATERIALS AND METHODS}

\section{Animals and Sample Collection}

All animal procedures were approved by the Michigan State University Animal Care and Use Committee. Six lactating, nongestating, multiparous Holstein cows were included in the study from the pool of cases admitted to the Training Center for Dairy Professionals, Michigan State University, for surgical correction of left DA. These animals were in their second $(\mathrm{n}=$ 4) or third $(\mathrm{n}=2)$ lactation, calved less than $15 \mathrm{~d}$ before left DA diagnosis (DIM $=7.8 \pm 4.6 \mathrm{~d}$ ), and had a BCS of $2.95 \pm 0.1$ as determined visually by an experienced technician using a 1 to 5 scale (Domecq et al., 1995). All cows had a previous lactation 305-d mature-equivalent milk production $>8,000 \mathrm{~kg}(9,045 \pm$ $684.2 \mathrm{~kg}$ ) and their last SCC in the previous lactation was $<200,000$ cells $/ \mathrm{mL}(60,500 \pm 21,780$ cells $/ \mathrm{mL})$. Before surgical procedure, blood samples $(20 \mathrm{~mL})$ were obtained by coccygeal venipuncture and collected in tubes with or without EDTA. Left DA corrections were performed via standing right-flank laparotomy using omentopexy as described previously (Niehaus, 2008). Adipose samples $(3-5 \mathrm{~g})$ from the omental $(\mathbf{O M})$ and 
subcutaneous (SC) adipose tissues were collected during surgery. The OM samples were harvested before abomasal fixation, and the SC specimens were obtained from the incision area before closure. In an effort to evaluate ATM infiltration in healthy cows in anabolic state (AS), adipose tissue and blood samples were collected from 6 healthy multiparous, nonlactating, nongestating Holstein dairy cows at a local abattoir. These cows had BCS >3.7 (3.75 \pm 0.12$)$. Blood was collected by coccygeal venipuncture before slaughter. The SC fat samples were harvested after skin removal from the right flank (matching surgical incision area in DA cases). The OM samples were collected at the time of evisceration from the abomasal area matching location in the DA cases.

\section{Sample Processing}

Immediately after collection, OM and SC adipose samples were placed on ice in Krebs Ringer bicarbonate buffered solution (KRBB) containing $50 \mu \mathrm{g} / \mathrm{mL}$ of gentamicin (MP Biochemicals, Solon, OH) and HEPES $10 \mathrm{~m} M(\mathrm{pH}=7.4)$ and transported immediately to the laboratory. Subsets of samples were collected in RNA later (Ambion, Carlsbad, CA) for quantitative (q) PCR analysis, flash frozen for protein analysis, or immersed in 4\% paraformaldehyde (Electron Microscope Sciences, Hatfield, PA) for immunohistochemistry. Plasma and serum were obtained from blood samples and submitted to the Diagnostic Center for Population and Animal Health (Michigan State University, East Lansing) for metabolic profiling as described previously (Kabara et al., 2014). The revised quantitative insulin sensitivity check index (RQUICKI) was calculated as described by Perseghin et al. (2001).

\section{Adipose Tissue Fractionation}

At the laboratory, $\mathrm{OM}$ and $\mathrm{SC}$ samples were first washed with KRBB and then minced in 2- to $3-\mathrm{mm}$ sections. Tissue digestion was performed in collagenase type II solution $(2 \mathrm{mg} / \mathrm{mL}$; Worthington Biochemical, Lakewood, NJ) in KRBB containing 3\% BSA in 50-mL centrifuge tubes. Samples in collagenase solution were incubated in a $37^{\circ} \mathrm{C}$ water bath with inversion of the vials every 5 min and then transferred to an incubator for further digestion with shaking for $45 \mathrm{~min}$ at $37^{\circ} \mathrm{C}$ and $230 \mathrm{rpm}$. After incubation, digested material was sequentially filtered through 1,000-, 500-, and 53- $\mu \mathrm{m}$ sterilized screens (Solstas Labpartners, Greensboro, $\mathrm{NC})$. Resulting filtrate was centrifuged at $4^{\circ} \mathrm{C}$ for 10 min at $800 \times g$. Pellets containing the SVF cells were resuspended in erythrocyte lysis buffer solution $(5 \mathrm{~mL})$ containing $154 \mathrm{~m} M$ ammonium chloride, $10 \mathrm{~m} M$ potas- sium bicarbonate, and $0.1 \mathrm{~m} M$ EDTA and rocked on a platform for $5 \mathrm{~min}$ at room temperature. The SVF suspensions were centrifuged at $4^{\circ} \mathrm{C}$ for 10 min at 800 $\times g$ and then resuspended in fluorescence-activated cell sorting (FACS) solution containing PBS, $10 \%$ sodium azide solution, $2 \%$ fetal bovine serum, and $0.5 \mathrm{mM}$ EDTA for flow cytometry analysis. An SVF subsample was collected in RNA later for gene expression analysis.

\section{Flow Cytometry}

To determine adipose tissue macrophage distribution and phenotype in SVF, cell suspensions were incubated with mouse-derived antibodies against leukocyte antigens, as described previously (O'Boyle et al., 2012). Antibodies used were from the Washington State University monoclonal antibody center (Pullman): CD3 (MM1A; 1:100), CD11c (BAQ153A; 1:100), CD14 (MM61A; 1:50), CD172a (DH59B; 1:100); and AbD Serotec (Raleigh, NC): CD163 (MCA2311GA; 1:100). After a 30-min incubation at $4^{\circ} \mathrm{C}$, cells were washed 3 times with FACS solution. Next, SVF cells were incubated for $30 \mathrm{~min}$ at $4^{\circ} \mathrm{C}$ with the corresponding secondary antibody that included either goat anti-mouse IgM (Santa Cruz Biotechnology, Dallas, TX) for CD11c, or goat anti-mouse IgG for all others (Jackson ImmunoResearch, West Grove, PA). Following secondary antibody exposure, cells were again washed with FACS solution 3 times. Finally, SVF cells were fixed with $2 \%$ formaldehyde solution and stored out of direct light for up to 3 d. Flow cytometry analysis was performed using the FACSdiva software on an LSRII Flow Cytometer (BD Biosciences, San Jose, CA).

\section{Gene Expression Analysis by Quantitative PCR}

Adipose tissue RNA was extracted using Trizol reagents (Life Technologies, Grand Island, NY) according to the manufacturer's directions and then purified using the RNA Easy Mini Kit (Qiagen, Valencia, CA) as described previously (Contreras et al., 2014). The SVF cells were homogenized using the QIAshredder system (Qiagen) and RNA was extracted using the RNA Easy Mini Kit (Qiagen). Purity, concentration, and integrity of mRNA were evaluated using a NanoDrop 1000 spectrophotometer (Thermo Scientific, Wilmington, DE) and an Agilent Bioanalyzer 2100 (Agilent Technologies, Santa Clara, CA) system. All samples had a 260:280 $\mathrm{nm}$ ratio between 1.9 and 2.1 and an RNA integrity number $>6$. Conversion to cDNA was performed using the Applied Biosystems High Capacity cDNA Archive Kit (Applied Biosystems, Foster City, CA). All quantitative PCR assays were conducted with TaqMan gene expression assays from Applied Biosystems. TaqMan 
primer and probe bovine-specific sets were either commercially available or designed from bovine sequences with the Applied Biosystems Pipeline software and synthesized by Applied Biosystems Inc. (Table 1). Samples were assayed in triplicate using the 7800 PCR System (Applied Biosystems). Relative quantification was calculated using SDS Software (Applied Biosystems). Appropriate controls were selected as described by (Steibel et al., 2009) using Data Assist software (Applied Biosystems) and included EFI3K, B2M, and RPS9. For reporting, expression data were normalized to the mean of these housekeeping genes.

\section{Immunohistochemistry}

To determine the localization of macrophages within the adipose tissue, immunostaining was performed in paraffin sections of $\mathrm{OM}$ and $\mathrm{SC}$ adipose depots using the Autostainer Link 48 (Dako North America Inc., Carpinteria, CA) automated stainer and a mouse monoclonal antibody against CD172a (DH59B) at a dilution of 1:100. After fixation with $4 \%$ formalin, samples were embedded in paraffin and cut into $5-\mu \mathrm{m}-$ thick sections. Deparaffinization and antigen retrieval of formalin-fixed paraffin embedded tissues were performed on the PT Link (Dako North America Inc.) using the Dako Target Retrieval Solution, Citrate pH 6 (Dako North America Inc.). Detection of the target was achieved using the EnVision Flex+ detection system (Dako North America Inc.), the immunoreaction was visualized with 3,3-diaminobenzidine substrate (Dako North America Inc.), and sections were counterstained with hematoxylin. Positive immunohistochemical controls included bovine spleen and stromal vascular fraction cell pellets that had also been fixed in formalin and paraffin embedded. For negative controls, the primary antibodies were replaced with homologous nonimmune sera. Cellular aggregates were defined as clusters of CD172a-positive cells that were quantified within 100 contiguous adipocytes from 5 randomly selected fields per section. Imaging was performed using an Olympus BX-40 microscope (Olympus, Center Valley, PA). Adipocyte cell diameters were determined as described by (Verdes et al., 2013) using hematoxylin- and eosinstained paraffin sections. Diameters of 100 adjacent cells from 5 randomly selected fields per section were measured using ImageJ software (National Institutes of Health, Bethesda, MD).

Table 1. Sequences of PCR primers and probes, and PCR product length

\begin{tabular}{|c|c|c|c|c|}
\hline Target & $\begin{array}{l}\text { Accession no., } \\
\text { TaqMan assay ID, } \\
\text { and reference }\end{array}$ & & Sequence $\left(5^{\prime}\right.$ to $\left.3^{\prime}\right)$ & $\begin{array}{l}\text { PCR product } \\
\text { length, bp }\end{array}$ \\
\hline \multirow[t]{2}{*}{ CCL2 } & NM_174006.2 & Forward & GAGTCACCAGCAGCAAGTGT & \multirow[t]{2}{*}{94} \\
\hline & & Probe & CGCTCAGCCAGATGCAATTAACTCC & \\
\hline \multirow[t]{3}{*}{$\mathrm{FABP}_{4}$} & NM_174314.2 & Forward & GTCATGAATGGTGTCACTGCC & \multirow[t]{3}{*}{93} \\
\hline & Bt03213820_m1 & Reverse & GGAGTTCGATGCAAACGTCA & \\
\hline & & Probe & CATGAAAGAAGTGGGCGTGGGCTTT & \\
\hline & & Probe & GTCCAAGACAGAGCCAATGCGGCGC & 84 \\
\hline \multirow[t]{3}{*}{ IL 6} & NM_173923.2 & Forward & ACCCCAGGCAGACTACTTCT & \multirow[t]{3}{*}{115} \\
\hline & Bt03211905_m1 & Reverse & TCGACCATGCGCTTAATGAGA & \\
\hline & & Probe & TCCTGAAGCAAAAGATCGCAGATCT & \\
\hline \multirow[t]{2}{*}{ SIRPA } & NM_175788.1; Y11045.1 & Forward & TGGACCAGCATCTTCATCGT & \multirow[t]{2}{*}{91} \\
\hline & Bt03224468_m1 & Reverse & TCTGTCTGATTCGGAGGAGGT & \\
\hline & Bt03259156_m1 & Reverse & GGGCTACCGGCTTGTTACTT & \multirow{2}{*}{69} \\
\hline & (Raphael et al., 2014) & Probe & CCCCCAGAGGGAAGAGCAGTCCCCA & \\
\hline \multirow[t]{3}{*}{ B2M } & NM_173893.3 & Forward & AGTGGAGGTGCTGGCATCTTA & \multirow[t]{3}{*}{76} \\
\hline & Bt03251628_m1 & Reverse & GCAGAAGACACCCAGATGTTGA & \\
\hline & & Probe & ATCGACAGGTACAACCCTGAGAACC & \\
\hline \multirow[t]{3}{*}{$R P S 9$} & NM_001101152 & Forward & GGCGGCTCGTCCGTATC & \multirow[t]{3}{*}{78} \\
\hline & (Mattmiller et al., 2011) & Reverse & AATCTTCAGGCCCAGGATGTAATC & \\
\hline & & Probe & CCCTCATCCAGCACCC & \\
\hline \multirow[t]{3}{*}{ EIF3K } & NM_001034489.2 & Forward & GTCGTGGGCATCACGTATCA & \multirow[t]{3}{*}{57} \\
\hline & Bt03226565_m1 & Reverse & CTGGCTGTCTGTCAGATCCC & \\
\hline & & Probe & ACGACAGGTACAACCCTGAGAACC & \\
\hline
\end{tabular}

${ }^{1}$ Life Technologies Corp. (Grand Island, NY). 


\section{Statistical Analyses}

Statistical evaluation was conducted using Proc MIXED (SAS version 9.1, SAS Institute Inc., Cary, NC). The linear mixed model included the fixed effects of disease, adipose tissue site, and their interaction and the random effect of cow. Comparisons of the means were made by ANOVA followed by Tukey-Kramer's honestly significant difference (HSD) post hoc test as necessary. Data are shown as means \pm standard errors of the mean (SEM). Differences with $P<0.05$ were considered statistically significant.

\section{RESULTS}

\section{Lipolysis in Cows with DA}

As expected, cows with DA were in an intense lipolytic state as demonstrated by elevated plasma NEFA (i.e., $>0.72 \mathrm{mEq} / \mathrm{L}$ ) and BHBA (Figure 1A). In contrast, cows in the AS group had mean NEFA concentrations of $0.40 \pm 0.16 \mathrm{mEq} / \mathrm{L}$, reflecting their fasted state, and low BHBA (Figure 1A). High rates of lipolysis in the DA group were reflected in significantly smaller OM and SC adipocyte diameters compared with those of AS cows (Figure 1A). The expression of the lipolytic gene LIPE, encoding hormone-sensitive lipase, and the fatty acid transporter fatty acid binding protein 4 (FABP 4) were significantly upregulated in DA cows compared with those in the AS group (Figure 1B). No differences were observed in plasma concentrations of insulin, glucose, or RQUICKI between DA and AS cows (Figure 1C).

\section{ATM Infiltration in Cows with DA}

Cows with DA had a significantly higher number of SVF cells expressing macrophage-specific cell surface markers CD172a and CD14 in OM compared with SC (Table 2). In contrast, AS cows showed no differences in the number of cells expressing these macrophage markers between the 2 anatomical sites (Table 2). Overall, the number of SVF cells expressing CD172a and CD14 was higher in OM of DA cows compared with OM and SC in AS cows (Table 2). The number of SVF cells expressing macrophage inflammatory phenotype markers CD11c and CD163 was higher in both adipose sites in DA cows compared with AS cows. No differences were observed in the expression of the T-cell specific marker CD3 between DA and AS cows or between OM and SC (Table 2). Gene expression analysis of SVF demonstrated that the expression of M1 phenotype-related genes including CCL2 and IL6 was significantly upregulated in $\mathrm{OM}$ of $\mathrm{DA}$ cows compared with $\mathrm{SC}$ in the same group of cows and $\mathrm{OM}$ and $\mathrm{SC}$ in the AS group (Figure 2). At the same time, signal regulatory protein $\alpha(S I R P A)$, the gene encoding for CD172a, and $T N F \alpha$ were upregulated in both sites in DA cows compared with AS (Figure 2).

\section{ATM Infiltration Is Localized in Cows with DA}

Immunohistochemical analysis of OM and SC depots of cows with DA using an antibody against the macrophage-specific marker CD172a demonstrated that ATM infiltration was localized in aggregates that included multinuclear cells (Figure 3). In contrast, ATM in AS were sparse and randomly localized in both $\mathrm{SC}$ and OM. The number of ATM aggregates per 100 adipocytes was significantly higher in DA cows compared with AS cows (Figure 3).

\section{DISCUSSION}

Excessive NEB, characterized by high lipolysis rates, is strongly associated with the development of DA in transition dairy cows (Cameron et al., 1998; Ospina et al., 2010). As described recently in rodents, humans, and dairy cattle, lipolysis in adipose tissues induces a remodeling process that is characterized by ATM infiltration and the development of an inflammatory process (Kosteli et al., 2010; Schmitt et al., 2011; Akter et al., 2012; Martinez-Santibañez and Nien-Kai Lumeng, 2014). In this study, we report infiltration of ATM forming multiple cellular aggregates in adipose tissues of dairy cows with DA that was concomitant with enhanced expression of pro-inflammatory cytokines and intense lipolysis rates.

Cows with DA in the present study were actively mobilizing lipids from adipose tissues. This was reflected in high concentrations of circulating NEFA and BHBA and smaller adipocyte sizes compared with those cows in the AS group. Adipocyte volume reduction from the end of the dry period up to peak lactation is an important characteristic of NEB in transition dairy cows (Akter et al., 2011; Verdes et al., 2013). Although we did not evaluate adipocyte size changes in the same animal through the transition period, it is expected that the smaller size of these cells in DA cows was reflective of the lipolytic process indicated by plasma NEFA. High lipid mobilization rates were also reflected in increased gene expression of LIPE in DA cows compared with that observed in AS animals. Expression of LIPE peaks around parturition and gradually decreases as lactation progresses (Elis et al., 2013; Khan et al., 2013). In transition cows, the activity of hormone-sensitive lipase reflects its encoding gene expression patterns, with higher phosphorylation rates around parturition that 
A.
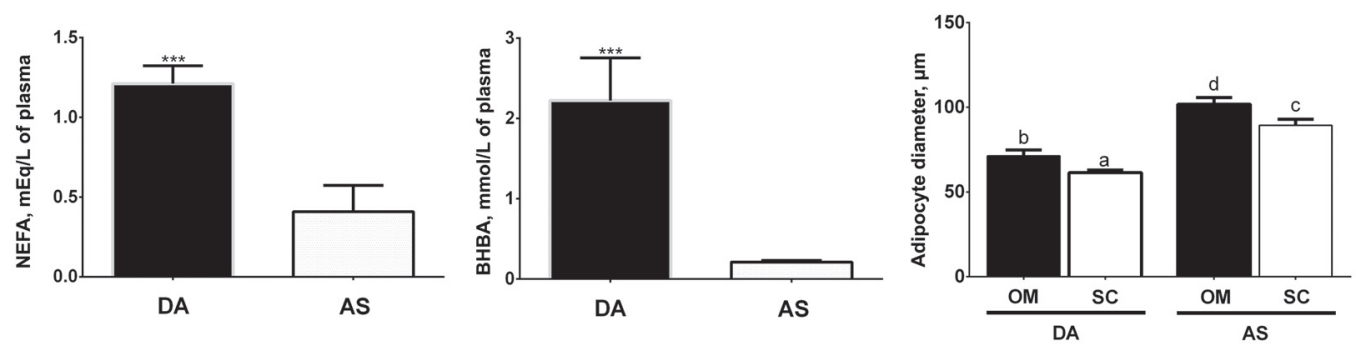

B.
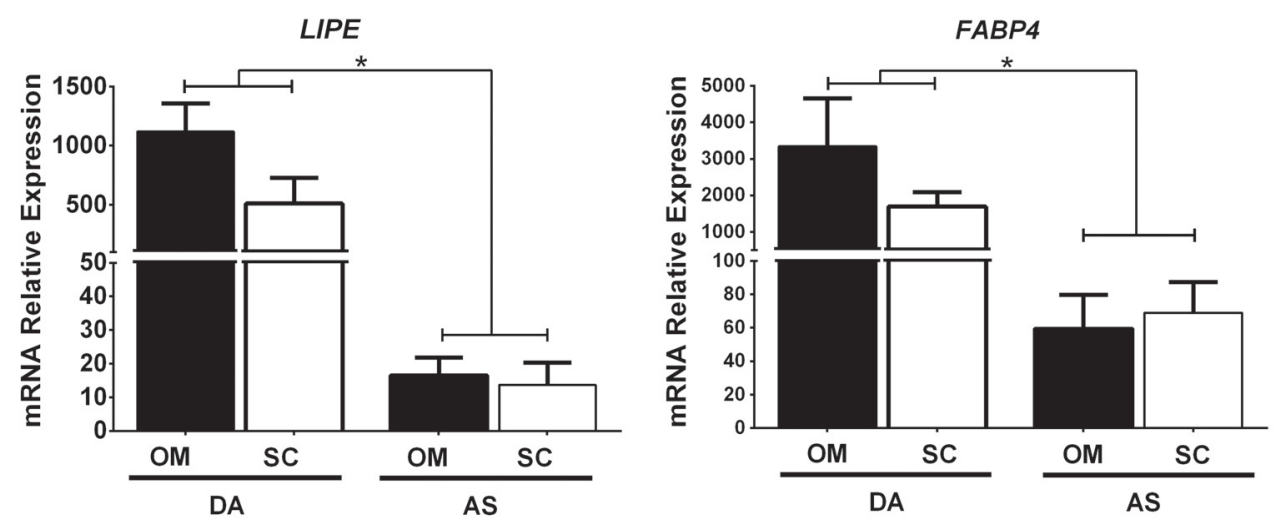

C.
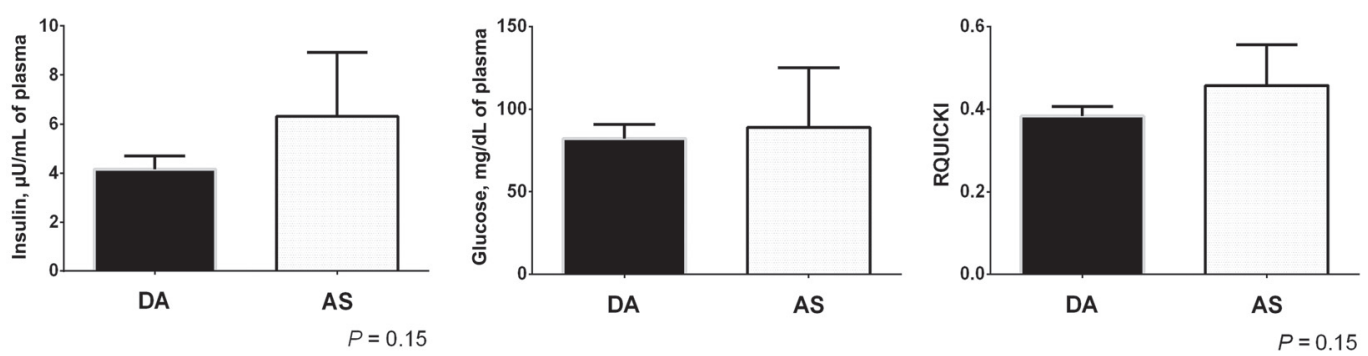

Figure 1. (A) Lipolysis markers in transition cows with displaced abomasum (DA) and healthy nongestating nonlactating cows (AS) including plasma concentrations of NEFA and BHBA and adipocyte diameters in adipose tissues collected form omental (OM) and subcutaneous (SC) depots. (B) Gene expression of lipolysis-related genes: hormone-sensitive lipase ( $L I P E$ ) and fatty acid binding protein 4 (FABP4) normalized to the mean of EFI3K, B2M, and RPS9 housekeeping genes. (C) Insulin sensitivity markers in DA and AS cows including: insulin, glucose, and the revised quantitative insulin sensitivity check index (RQUICKI). Data are means \pm SEM $(\mathrm{n}=6)$; significant differences: ${ }^{*} P<0.05,{ }^{* * *} P<$ 0.001. Means without a common letter $(\mathrm{a}-\mathrm{d}) \operatorname{differ}(P<0.05)$.

decrease after the third week of lactation (Koltes and Spurlock, 2011). Expression of FABP\& was upregulated in DA cows in the current study. This transporter is a chaperone for fatty acids after their release from lipid droplets by hormone-sensitive lipase and its expression is necessary for effective lipolysis (Furuhashi et al., 2011). The high lipolytic rate observed in cows with DA presents a unique opportunity to evaluate the ef- fects of lipolysis on inflammatory responses in adipose tissues.

To our knowledge, this is the first study reporting ATM trafficking and inflammatory phenotypes in OM and SC depots in nonlactating, nongestating cows and in DA cases using flow cytometry. In AS cows, around $10 \%$ of cells in SVF were considered mononuclear cells $\left(\mathrm{CD} 172 \mathrm{a}^{+}\right)$; this percentage is similar to those observed 
Table 2. Infiltration of macrophages into omental and subcutaneous adipose tissues in cows with displaced abomasum ${ }^{1}$

\begin{tabular}{|c|c|c|c|c|c|c|}
\hline Group & Site & \multicolumn{5}{|c|}{ Marker } \\
\hline DA & Omental & $9.29 \pm 1.94^{\mathrm{b}}$ & $20.28 \pm 1.57^{\mathrm{b}}$ & $10.44 \pm 0.75^{\mathrm{b}}$ & $5.70 \pm 1.37^{\mathrm{b}}$ & $4.50 \pm 0.62$ \\
\hline AS & Omental & $2.01 \pm 0.76^{\mathrm{a}}$ & $9.21 \pm 0.50^{\mathrm{a}}$ & $2.36 \pm 0.26^{\mathrm{a}}$ & $1.61 \pm 0.28^{\mathrm{a}}$ & $3.83 \pm 1.13$ \\
\hline AS & Subcutaneous & $1.29 \pm 0.22^{\mathrm{a}}$ & $10.92 \pm 0.51^{\mathrm{a}}$ & $1.74 \pm 0.25^{\mathrm{a}}$ & $0.72 \pm 0.38^{\mathrm{a}}$ & $3.70 \pm 0.60$ \\
\hline
\end{tabular}

${ }_{\mathrm{a}, \mathrm{b}}$ Means without a common superscript within each specific cluster of differentiation group differ $(P<0.05)$

${ }^{1}$ Data show distribution of macrophage markers CD14, CD172a, CD11c, CD163, and T-cell marker CD3 in stromal vascular fraction (SVF) cells of omental $(\mathrm{OM})$ and subcutaneous (SC) adipose tissue depots from cows with displaced abomasum (DA) and healthy nonlactating nongestating cows (AS). Values are percentage of the SVF population \pm SEM as measured by flow cytometry.
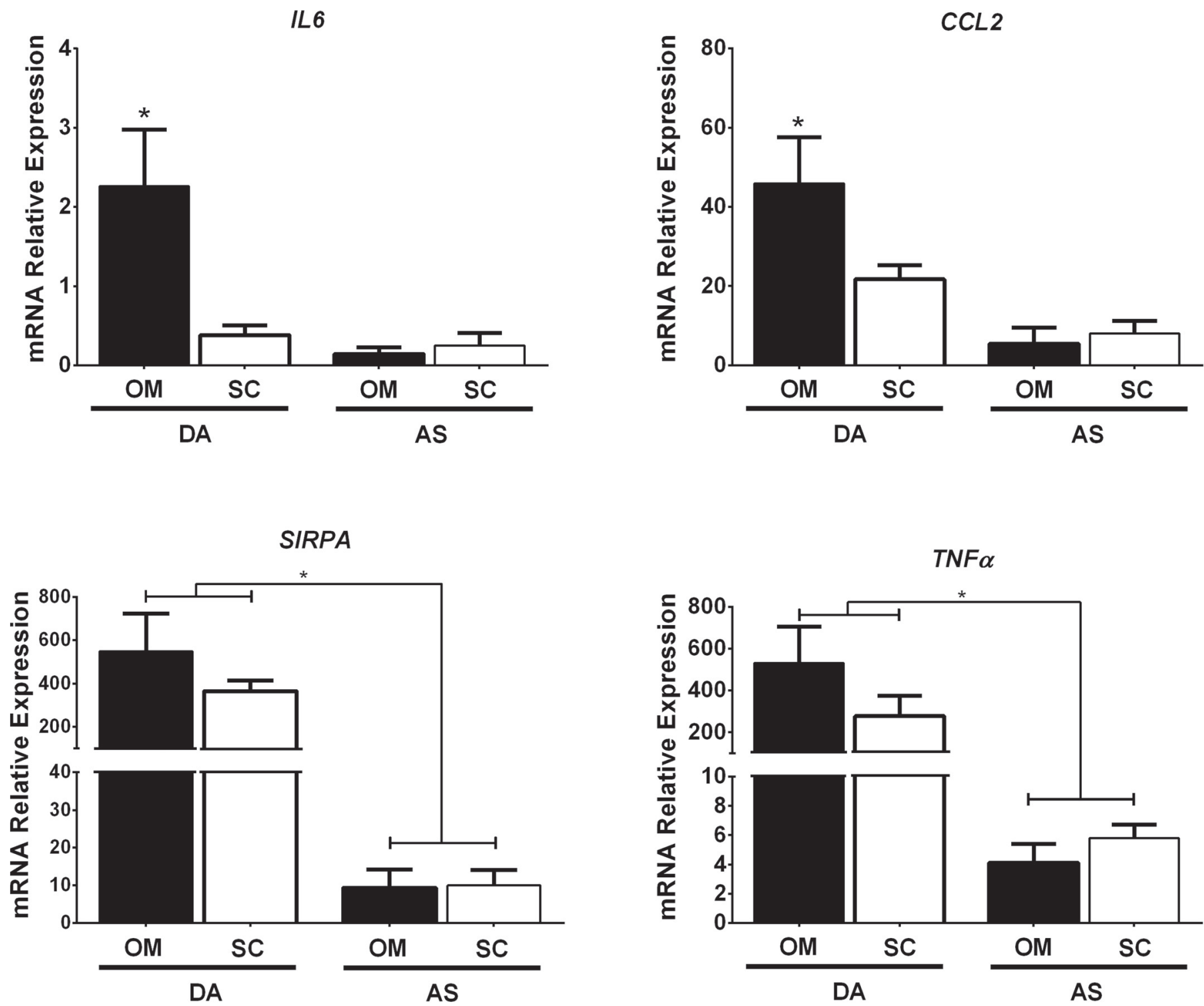

Figure 2. Expression of macrophage associated genes in adipose tissues of cows with displaced abomasum. Adipose tissue samples were collected from omental (OM) and subcutaneous (SC) depots from early lactation cows with displaced abomasum (DA) and healthy nongestating, nonlactating cows (AS). Gene expression of IL-6 (IL6), chemokine (C-C motif) ligand 2 (CCL2), signal regulatory protein $\alpha$ (SIRPA), and tumor necrosis factor $\alpha(T N F \alpha)$ normalized to the housekeeping genes EFI3K, B2M, and RPS9. Data are means \pm SEM (n $=6$ ); significant differences: ${ }^{*} P<0.05$. 
$\mathbf{A}$

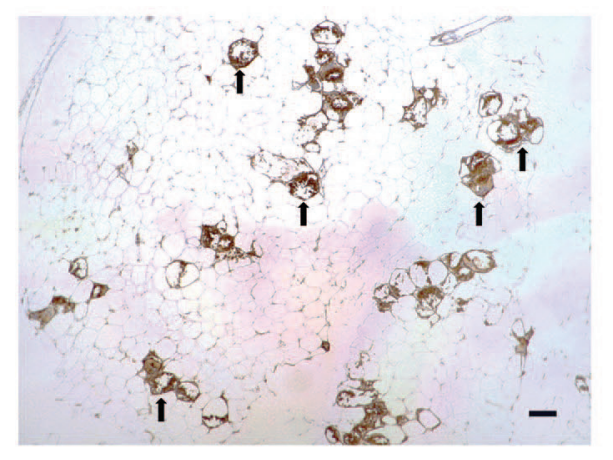

B

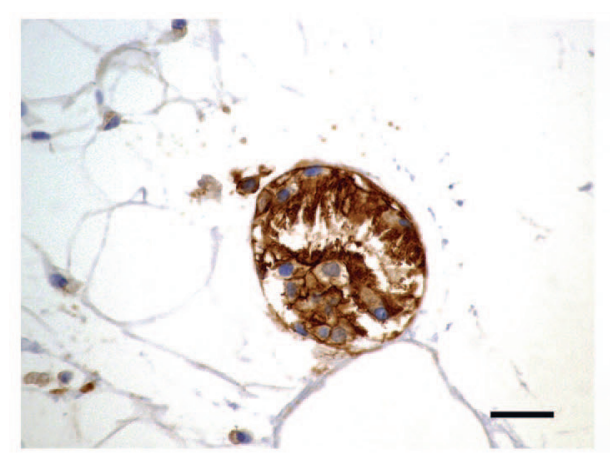

C

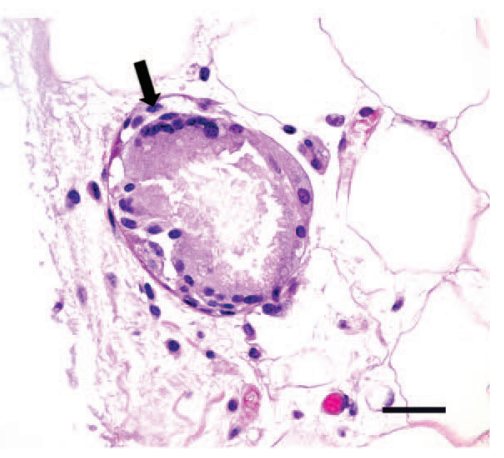

D

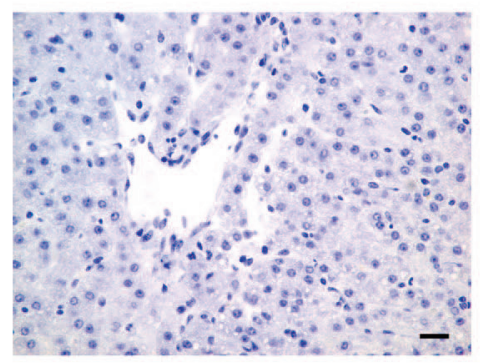

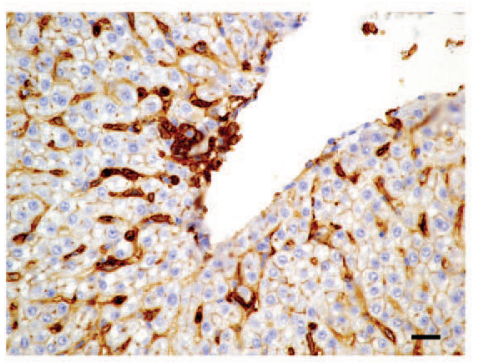

$\star *$

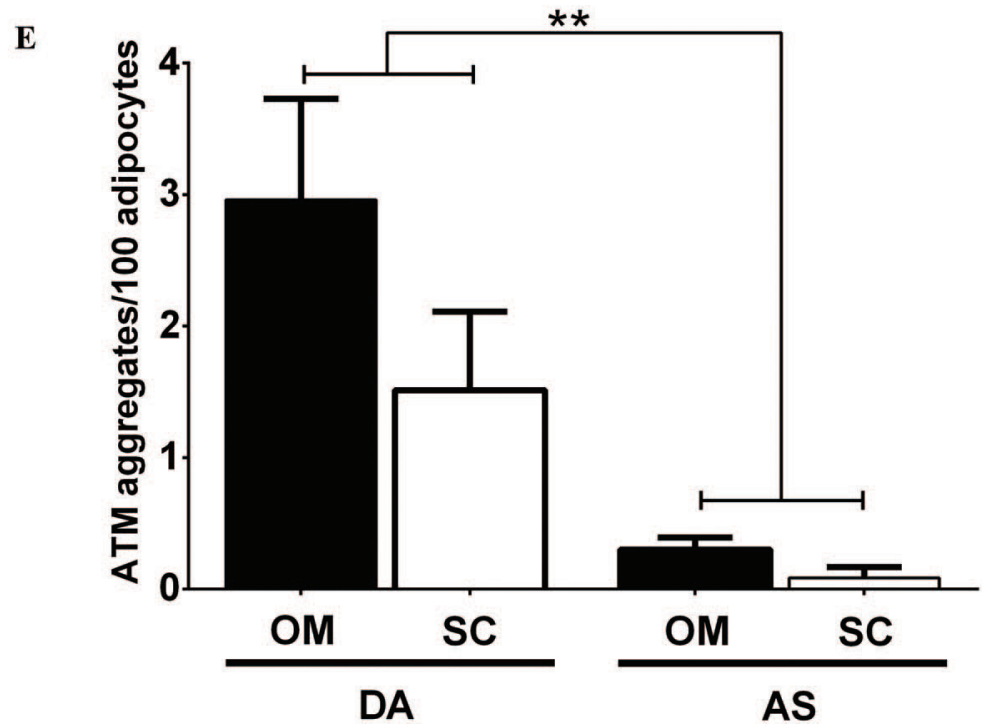

Figure 3. Adipose tissue macrophage (ATM) infiltration is localized in cows with displaced abomasum (DA). Low (A) and high (B) magnification images of omental adipose tissue $(\mathrm{OM})$ from a cow with displaced abomasum. Black arrows indicate immunoreactive CD172a macrophages localized in aggregates within OM. Scale bars $=30 \mu \mathrm{m}$; (C) high magnification image of an ATM aggregate that includes multinucleated cells (black arrow) stained with hematoxylin and eosin; (D) representative images of spleen with and without primary antibody (anti-CD172a); (E) ATM aggregates per 100 adipocytes in OM and subcutaneous adipose tissue (SC) of DA and healthy nongestating nonlactating cows (AS). Data are means \pm SEM $(\mathrm{n}=6)$; significant differences: ${ }^{* *} P<0.01$. Color version available online.

in lean mice, rats, and humans (Weisberg et al., 2003; Bourlier et al., 2008). Remarkably, in OM of DA cows, the percentage of $\mathrm{CD} 172 \mathrm{a}^{+}$in the SVF doubled to nearly $20 \%$. Greater infiltration of mononuclear cells is observed in obese rodents and humans where macrophage populations reach $50 \%$ of the SVF populations in visceral adipose depots (Lumeng et al., 2007). In these species, the number of macrophages is positively correlated with adipocyte size (Weisberg et al., 2003). In contrast to obese rodents and humans, ATM infiltration in dairy cows appears not to be associated with adipocyte size. In the current study, despite smaller 
OM adipocytes, DA cows had significant ATM infiltration. Conversely, no ATM infiltration was observed in dairy cows after feeding, for $9 \mathrm{wk}$, a high-concentrate diet that increased their fat mass and adipocytes size (Häussler, 2014). A second important finding from the flow cytometry analysis was that OM SVF cells from DA cows had increased expression of CD14. This macrophage-specific marker is a pattern recognition receptor for different ligands, including LPS, and apoptotic cells (Jersmann, 2005). Activation of CD14 is necessary for the phagocytosis of gram-negative bacteria and apoptotic cells and its expression increases during sepsis and adipose tissue remodeling processes (Devitt et al., 1998; Bourlier et al., 2008). Higher expression of CD14 in DA cows may be directly related to the adipose tissue remodeling process, as endotoxemia is infrequently present in transition dairy cows with DA (Wittek et al., 2004).

Infiltration of ATM in adipose tissues of DA cows opens the question as to the mechanisms leading to this cellular infiltration. The histologic appearance of ATM aggregates in DA cows, which includes the presence of multinucleated cells, shows similarities with localized areas of fat necrosis observed in cases of pancreatitis, abdominal trauma, and obesity. In peri-pancreatic and omental adipose tissues of dogs and humans with subclinical and chronic pancreatitis (Newman et al., 2004; Yadav and Lowenfels, 2013), leakage of lipases from inflamed areas of the pancreas into the abdominal cavity causes enzymatic digestion of adipocytes' lipid content, releasing free fatty acids (NEFA), phospholipids, and other lipids into the adipose milieu (Mateu et al., 2014). These lipid products induce an inflammatory response that is characterized by an accumulation of macrophages surrounding necrotic adipocytes or lipid remnants (Franco-Pons et al., 2013). Pancreatitis is rarely diagnosed in dairy cattle and therefore it is unknown if its specific biomarkers, such as plasma pancreatic lipase, are altered in cows with DA or during NEB in transition cattle. Further studies are required to evaluate the dynamics of plasma pancreatic lipases and other biomarkers of pancreatitis in DA cows. A second possibility is that ATM infiltration was a consequence of adipose tissue trauma during the displacement of the abomasum and its associated tissues. However, the presence of ATM infiltration in the SC tissue and the limited size of the ATM aggregations in OM may not support this possibility. A third option is that ATM infiltration was lipolysis driven. This would coincide with recent discoveries in rodents and humans which have demonstrated that lipolysis is the triggering stimulus for ATM infiltration (Kosteli et al., 2010). Aggregates of ATM were described in both species during disease and physiological processes associated with high rates of lipolysis such as obesity, extreme caloric restriction, and pharmacological activation of adrenergic receptors (Cinti et al., 2005; Bourlier et al., 2008; Kosteli et al., 2010). In these monogastric animals, mononuclear cell aggregates surrounding necrotic adipocytes, lipid remnants, or triglycerides are termed "crown-like structures" (CLS; Murano et al., 2008). As in focal fat necrosis associated with pancreatitis, ATM aggregation in CLS localizes lipids within the adipose tissue, preventing lipotoxicity (Sun et al., 2011). Further studies are needed to determine if ATM aggregates observed in cows with DA can be defined as CLS and to understand the effect that these structures have on adipose tissue metabolic function.

In the present study, OM and SC SVF cells from DA cows had enhanced expression of TNFo compared with AS cows. In adipose tissues, this pro-inflammatory cytokine is secreted by adipocytes and macrophages; it activates inflammatory pathways including JNK and $\mathrm{NF \kappa B}$, which inhibit adipogenesis (i.e., preadipocytes differentiation into adipocytes), insulin-mediated lipogenesis, and glucose uptake through glucose transporters (Cawthorn and Sethi, 2008). At the same time, $\mathrm{TNF} \alpha$ promotes lipolysis, thus increasing the concentration of NEFA in the adipose milieu and systemically (Chen et al., 2009). In nonruminants, classically activated (M1) ATM are the main source of TNFo in adipose tissues. The production of this cytokine by these cells is triggered by the presence of apoptotic adipocytes and extracellular lipids (Cinti et al., 2005). Dairy cows with DA have increased concentrations of plasma TNFo (Avki et al., 2004); however, the cellular sources of this cytokine during the pathogenesis of the disease are unclear and the relevance of adipose tissues cellular components as a source of $\mathrm{TNF} \alpha$ remains to be elucidated.

The expression of M1-related genes, including CCL2 and $I L 6$, was upregulated in DA cows. At the same time, these animals had increased SVF cell populations expressing the surface protein CD11c that is essential for phagocytosis, immune surveillance, and antigen presentation in M1 macrophages and dendritic cells (Lumeng et al., 2007). It is important to note the increased expression of CD163 in SVF cells of OM and SC from DA cows. This protein, also known as hemoglobin scavenger receptor, is exclusively expressed on cells of the monocyte lineage in cattle (Sopp et al., 2007); CD163 functions as a receptor for hemoglobin-haptoglobin complexes and bacteria that activates the expression of pro- and anti-inflammatory cytokines (Fabriek et al., 2009). Although the expression of CD163 was linked to the M2 phenotype (Fujisaka et al., 2009), recent studies in humans have described this marker in M1 macrophages and suggest that CD163 must be co-expressed 
with other surface markers for accurate phenotypic classification (Barros et al., 2013). These gene and protein expression profiles in $\mathrm{OM}$ and $\mathrm{SC}$ from cows with DA suggest a polarization toward macrophage M1 phenotype in infiltrating ATM. The mechanisms triggering this phenotype change are unclear but high lipolytic rates may play an important role. In rodents and humans, extended periods of enhanced lipolysis, such as those observed in obesity (Arner and Langin, 2014), promote ATM infiltration and the majority of these mononuclear cells are M1. In contrast, short periods of intense demand lipolysis promote a lower degree of ATM infiltration and these cells exhibit a predominant M2 phenotype (Bourlier et al., 2008). Although conjecture, DA cows in the present study could have experienced an extended period of lipolysis in the weeks before the abomasal displacement that led to ATM pro-inflammatory polarization in adipose tissues. Characterizing ATM infiltration and phenotypes in healthy and diseased transition dairy cows and their association with lipolysis rates may reveal pathogenic links between NEB and inflammatory diseases in early lactation.

Infiltration of M1 ATM is associated with the development of insulin resistance. In rodent and human obesity, the macrophage phenotypic switch from M2 to M1 is part of the pathophysiological mechanisms that lead to impaired insulin signaling in adipose tissues (Sell et al., 2012). As macrophages increase in numbers within the adipose, the expression of pro-inflammatory cytokines, including IL1 $\beta$, IL6, and TNF $\alpha$, is enhanced (Sun et al., 2011). High NEFA concentrations, in turn, promote lipotoxic-induced insulin resistance in adipose and other organs (Cusi, 2012). Given the M1 polarization of ATM in DA cows, we expected that these animals would have impaired systemic insulin sensitivity; however, RQUICKI values did not differ from those in AS cows. Recent findings provide evidence for adipose-specific insulin resistance during early lactation in cows prone to weight loss and high rates of lipid mobilization (Zachut et al., 2013). This study did not evaluate adipocyte insulin signaling function, thus it is presently unclear if an association exists between ATM infiltration and impaired adipose tissue insulin sensitivity in dairy cows with DA, and this warrants further investigation.

This study demonstrated increased infiltration of ATM forming aggregates in OM and SC and enhanced lipolysis rates in transition dairy cows with DA. The surface expression of macrophage markers in the stromal vascular cells and their gene expression profile indicate that these ATM may be polarized toward the M1 pro-inflammatory phenotype. The metabolic con- sequences of such inflammatory response are unknown and should be the focus of further studies.

\section{ACKNOWLEDGMENTS}

This project was supported in part by USDA-NIFA (Washington, DC) grants 2012-67012-19832 and 201567015-23207, Department of Large Animal Clinical Sciences (East Lansing, MI), the Michigan State University Elwood Kirkpatrick Dairy Science Research Endowment (East Lansing, MI), and CVM Venture and Last Lecture Fund (East Lansing, MI). The authors acknowledge the support of Vengai Mavangira at Training Center for Dairy Professionals (Elsie, MI), and Green Meadows Farm (Elsie, MI).

\section{REFERENCES}

Ackermann, M. R., B. M. DeBey, T. J. Stabel, J. H. Gold, K. B. Register, and J. T. Meehan. 1994. Distribution of anti-CD68 (EBM11) immunoreactivity in formalin-fixed, paraffin-embedded bovine tissues. Vet. Pathol. 31:340-348.

Akter, S. H., S. Häussler, S. Dänicke, U. Müller, D. von Soosten, J. Rehage, and H. Sauerwein. 2011. Physiological and conjugated linoleic acid-induced changes of adipocyte size in different fat depots of dairy cows during early lactation. J. Dairy Sci. 94:2871-2882.

Akter, S. H., S. Häussler, D. Germeroth, D. von Soosten, S. Dänicke, K. H. Südekum, and H. Sauerwein. 2012. Immunohistochemical characterization of phagocytic immune cell infiltration into different adipose tissue depots of dairy cows during early lactation. J. Dairy Sci. 95:3032-3044.

Arner, P., and D. Langin. 2014. Lipolysis in lipid turnover, cancer cachexia, and obesity-induced insulin resistance. Trends Endocrinol. Metab. 25:255-262.

Avki, S., A. Simsek, H. Turutgolu, T. Ileri-Buyukoglu, K. Yigitarslan, and M. Temizsoylu. 2004. Serum tumor necrosis factor-alpha activity in dairy cows with abomasal displacement: The potential for anti-cytokine therapy. J. Turkish Vet. Surg. 10:28-32.

Barros, M. H. M., F. Hauck, J. H. Dreyer, B. Kempkes, and G. Niedobitek. 2013. Macrophage polarisation: An immunohistochemical approach for identifying M1 and M2 macrophages. PLoS ONE 8:e80908.

Bastos, R. G., W. C. Johnson, W. C. Brown, and W. L. Goff. 2007. Differential response of splenic monocytes and DC from cattle to microbial stimulation with Mycobacterium bovis BCG and Babesia bovis merozoites. Vet. Immunol. Immunopathol. 115:334-345.

Boulay, G., D. Francoz, E. Doré, S. Dufour, M. Veillette, M. Badillo, A. M. Bélanger, and S. Buczinski. 2014. Preoperative cow-side lactatemia measurement predicts negative outcome in Holstein dairy cattle with right abomasal disorders. J. Dairy Sci. 97:212-221.

Bourlier, V., A. Zakaroff-Girard, A. Miranville, S. De Barros, M. Maumus, C. Sengenes, J. Galitzky, M. Lafontan, F. Karpe, K. N. Frayn, and A. Bouloumié. 2008. Remodeling phenotype of human subcutaneous adipose tissue macrophages. Circulation 117:806-815.

Cameron, R. E. B., P. B. Dyk, T. H. Herdt, J. B. Kaneene, R. Miller, H. F. Bucholtz, J. S. Liesman, M. J. Vandehaar, and R. S. Emery. 1998. Dry cow diet, management, and energy balance as risk factors for displaced abomasum in high producing dairy herds. J. Dairy Sci. 81:132-139.

Cawthorn, W. P., and J. K. Sethi. 2008. TNF- $\alpha$ and adipocyte biology. FEBS Lett. 582:117-131.

Chawla, A., K. D. Nguyen, and Y. S. Goh. 2011. Macrophage-mediated inflammation in metabolic disease. Nat. Rev. Immunol. 11:738-749. 
Chen, X., K. Xun, L. Chen, and Y. Wang. 2009. TNF- $\alpha$, a potent lipid metabolism regulator. Cell Biochem. Funct. 27:407-416.

Cho, K. W., D. L. Morris, and C. N. Lumeng. 2014. Chapter 16: Flow cytometry analyses of adipose tissue macrophages. Pages 297-314 in Methods in Enzymology. Vol. 537. A. M. Ormond, ed. Academic Press, San Diego, CA.

Cinti, S., G. Mitchell, G. Barbatelli, I. Murano, E. Ceresi, E. Faloia, S. Wang, M. Fortier, A. S. Greenberg, and M. S. Obin. 2005. Adipocyte death defines macrophage localization and function in adipose tissue of obese mice and humans. J. Lipid Res. 46:2347-2355.

Contreras, G. A.. Y.-H. Lee, E. P. Mottillo, and J. G. Granneman. 2014. Inducible brown adipocytes in subcutaneous inguinal white fat: The role of continuous sympathetic stimulation. Am. J. Physiol. Endocrinol. Metab. 307:E793-E799.

Curat, C. A., V. Wegner, C. Sengenès, A. Miranville, C. Tonus, R Busse, and A. Bouloumié. 2006. Macrophages in human visceral adipose tissue: increased accumulation in obesity and a source of resistin and visfatin. Diabetologia 49:744-747.

Cusi, K. 2012. Role of obesity and lipotoxicity in the development of nonalcoholic steatohepatitis: Pathophysiology and clinical implications. Gastroenterology 142:711-725.e6.

Devitt, A., O. D. Moffatt, C. Raykundalia, J. D. Capra, D. L. Simmons, and C. D. Gregory. 1998. Human CD14 mediates recognition and phagocytosis of apoptotic cells. Nature 392:505-509.

Domecq, J. J., A. L. Skidmore, J. W. Lloyd, and J. B. Kaneene. 1995 Validation of body condition scores with ultrasound measurements of subcutaneous fat of dairy cows. J. Dairy Sci. 78:2308-2313.

Elis, S., S. Coyral-Castel, S. Freret, J. Cognié, A. Desmarchais, A Fatet, C. Rame, E. Briant, V. Maillard, and J. Dupont. 2013. Expression of adipokine and lipid metabolism genes in adipose tissue of dairy cows differing in a female fertility quantitative trait locus. J. Dairy Sci. 96:7591-7602.

Fabriek, B. O., R. van Bruggen, D. M. Deng, A. J. M. Ligtenberg, K. Nazmi, K. Schornagel, R. P. M. Vloet, C. D. Dijkstra, and T. K. van den Berg. 2009. The macrophage scavenger receptor CD163 functions as an innate immune sensor for bacteria. Blood 113:887-892

Ferrante, A. W. 2013. The immune cells in adipose tissue. Diabetes Obes. Metab. 15(Suppl. 3):34-38.

Franco-Pons, N., J. Casas, G. Fabriàs, S. Gea-Sorlí, E. de-Madaria, E. Gelpí, and D. Closa. 2013. Fat necrosis generates proinflammatory halogenated lipids during acute pancreatitis. Ann. Surg. 257:943-951.

Fujisaka, S., I. Usui, A. Bukhari, M. Ikutani, T. Oya, Y. Kanatani K. Tsuneyama, Y. Nagai, K. Takatsu, M. Urakaze, M. Kobayashi, and K. Tobe. 2009. Regulatory mechanisms for adipose tissue M1 and M2 macrophages in diet-induced obese mice. Diabetes $58: 2574-2582$

Furuhashi, M., S. Ishimura, H. Ota, and T. Miura. 2011. Lipid chaperones and metabolic inflammation. Int. J. Inflam. 2011:642612. http://dx.doi.org/10.4061/2011/642612.

Geishauser, T., T. Leslie, and T. Duffield. 1996. Prevention and prediction of displaced abomasum in dairy cows. Pages 203-207 in Proc. Annu. Conv. Am. Assoc. Bovine Pract., San Diego, CA. Am. Assoc. Bovine Pract., Auburn, AL.

Granneman, J. G., P. Li, Z. Zhu, and Y. Lu. 2005. Metabolic and cellular plasticity in white adipose tissue I: Effects of $\beta 3$-adrenergic receptor activation. Am. J. Physiol. Endocrinol. Metab. 289:E608E616.

Häussler, S. 2014. Macrophage infiltration into subcutaneous adipose tissue in overconditioned cows after excessive fat accumulation. J. Dairy Sci. 97(Suppl. 1):1385. (Abstr.)

Hussen, J., C. Frank, A. Düvel, M. Koy, and H.-J. Schuberth. 2014 The chemokine CCL5 induces selective migration of bovine classical monocytes and drives their differentiation into LPS-hyporesponsive macrophages in vitro. Dev. Comp. Immunol. 47:169-177.

Jersmann, H. P. A. 2005. Time to abandon dogma: CD14 is expressed by non-myeloid lineage cells. Immunol. Cell Biol. 83:462-467.

Kabara, E., L. M. Sordillo, S. Holcombe, and G. A. Contreras. 2014. Adiponectin links adipose tissue function and monocyte inflamma- tory responses during bovine metabolic stress. Comp. Immunol Microbiol. Infect. Dis. 37:49-58.

Khan, M. J., A. Hosseini, S. Burrell, S. M. Rocco, J. P. McNamara, and J. J. Loor. 2013. Change in subcutaneous adipose tissue metabolism and gene network expression during the transition period in dairy cows, including differences due to sire genetic merit. J. Dairy Sci. 96:2171-2182.

Kitani, H., M. Yoshioka, T. Takenouchi, M. Sato, and N. Yamanaka 2011. Isolation and characterization of macrophages from a mixed primary culture of bovine liver cells. Vet. Immunol. Immunopathol. 140:341-345.

Koltes, D. A., and D. M. Spurlock. 2011. Coordination of lipid dropletassociated proteins during the transition period of Holstein dairy cows. J. Dairy Sci. 94:1839-1848.

Kosteli, A., E. Sugaru, G. Haemmerle, J. F. Martin, J. Lei, R. Zechner, and A. W. Ferrante Jr.. 2010. Weight loss and lipolysis promote a dynamic immune response in murine adipose tissue. J. Clin. Invest. 120:3466-3479.

Lee, Y.-H., E. P. Mottillo, and J. G. Granneman. 2014. Adipose tissue plasticity from WAT to BAT and in between. Biochim. Biophys. Acta 1842:358-369.

Lumeng, C. N., J. L. Bodzin, and A. R. Saltiel. 2007. Obesity induces a phenotypic switch in adipose tissue macrophage polarization. J Clin. Invest. 117:175-184.

Martinez, F. O., S. Gordon, M. Locati, and A. Mantovani. 2006. Transcriptional profiling of the human monocyte-to-macrophage differentiation and polarization: New molecules and patterns of gene expression. J. Immunol. 177:7303-7311.

Martinez-Santibañez, G., and C. Nien-Kai Lumeng. 2014. Macrophages and the regulation of adipose tissue remodeling. Annu. Rev. Nutr. 34:57-76.

Mateu, A., L. Ramudo, M. A. Manso, D. Closa, and I. De Dios. 2014 Acinar inflammatory response to lipid derivatives generated in necrotic fat during acute pancreatitis. Biochim. Biophys. Acta 1842:1879-1886

Mattmiller, S. A., C. M. Corl, J. C. Gandy, J. J. Loor, and L. M. Sordillo. 2011. Glucose transporter and hypoxia-associated gene expression in the mammary gland of transition dairy cattle. J. Dairy Sci. 94:2912-2922.

Murano, I., G. Barbatelli, V. Parisani, C. Latini, G. Muzzonigro, M. Castellucci, and S. Cinti. 2008. Dead adipocytes, detected as crown-like structures, are prevalent in visceral fat depots of genetically obese mice. J. Lipid Res. 49:1562-1568.

Newman, S., J. Steiner, K. Woosley, L. Barton, C. Ruaux, and D. Williams. 2004. Localization of pancreatic inflammation and necrosis in dogs. J. Vet. Intern. Med. 18:488-493.

Niehaus, A. J. 2008. Surgery of the abomasum. Vet. Clin. North Am. Food Anim. Pract. 24:349-358.

O'Boyle, N. J., G. A. Contreras, S. A. Mattmiller, and L. M. Sordillo. 2012. Changes in glucose transporter expression in monocytes of periparturient dairy cows. J. Dairy Sci. 95:5709-5719.

Ospina, P. A., D. V. Nydam, T. Stokol, and T. R. Overton. 2010 Evaluation of nonesterified fatty acids and $\beta$-hydroxybutyrate in transition dairy cattle in the northeastern United States: Critical thresholds for prediction of clinical diseases. J. Dairy Sci 93:546-554.

Palmer, M. V., T. C. Thacker, and W. R. Waters. 2009. Histology, immunohistochemistry and ultrastructure of the bovine palatine tonsil with special emphasis on reticular epithelium. Vet. Immunol. Immunopathol. 127:277-285.

Perseghin, G., A. Caumo, M. Caloni, G. Testolin, and L. Luzi. 2001 Incorporation of the fasting plasma FFA concentration into QUICKI improves its association with insulin sensitivity in nonobese individuals. J. Clin. Endocrinol. Metab. 86:4776-4781.

Raphael, W., L. Halbert, G. A. Contreras, and L. M. Sordillo. 2014 Association between polyunsaturated fatty acid-derived oxylipid biosynthesis and leukocyte inflammatory marker expression in periparturient dairy cows. J. Dairy Sci. 97:3615-3625.

Saremi, B., S. Winand, P. Friedrichs, A. Kinoshita, J. Rehage, S. Dänicke, S. Häussler, G. Breves, M. Mielenz, and H. Sauerwein. 2014. 
Longitudinal profiling of the tissue-specific expression of genes related with insulin sensitivity in dairy cows during lactation focusing on different fat depots. PLoS ONE 9:e86211.

Schmitt, E., M. A. Ballou, M. N. Correa, E. J. DePeters, J. K. Drackley, and J. J. Loor. 2011. Dietary lipid during the transition period to manipulate subcutaneous adipose tissue peroxisome proliferator-activated receptor- $\gamma$ co-regulator and target gene expression. J. Dairy Sci. 94:5913-5925.

Seifi, H. A., S. J. LeBlanc, K. E. Leslie, and T. F. Duffield. 2011. Metabolic predictors of post-partum disease and culling risk in dairy cattle. Vet. J. 188:216-220.

Sell, H., C. Habich, and J. Eckel. 2012. Adaptive immunity in obesity and insulin resistance. Nat. Rev. Endocrinol. 8:709-716.

Shaver, R. D. 1997. Nutritional risk factors in the etiology of left displaced abomasum in dairy cows: A review. J. Dairy Sci. 80:24492453.

Sica, A., and A. Mantovani. 2012. Macrophage plasticity and polarization: In vivo veritas. J. Clin. Invest. 122:787-795.

Sopp, P., L. S. Kwong, and C. J. Howard. 1996. Identification of bovine CD14. Vet. Immunol. Immunopathol. 52:323-328.

Sopp, P., D. Werling, and C. Baldwin. 2007. Cross-reactivity of mAbs to human CD antigens with cells from cattle. Vet. Immunol. Immunopathol. 119:106-114.

Steibel, J. P., R. Poletto, P. M. Coussens, and G. J. M. Rosa. 2009. A powerful and flexible linear mixed model framework for the analysis of relative quantification RT-PCR data. Genomics 94:146-152.
Sterner, K. E., J. Grymer, P. C. Bartlett, and M. J. Miekstyn. 2008. Factors influencing the survival of dairy cows after correction of left displaced abomasum. J. Am. Vet. Med. Assoc. 232:1521-1529.

Sumner, J. M., and J. P. McNamara. 2007. Expression of lipolytic genes in the adipose tissue of pregnant and lactating Holstein dairy cattle. J. Dairy Sci. 90:5237-5246.

Sun, K., C. M. Kusminski, and P. E. Scherer. 2011. Adipose tissue remodeling and obesity. J. Clin. Invest. 121:2094-2101.

Verdes, J. M., L. Espino, A. Goicoa, L. Rigueira, L. A. Ramil, and L. E. Fidalgo. 2013. Quantification of pericaudal adipocyte diameter in dairy cattle during peripartum: A complementary method to study energetic status using conventional histology. J. Anim. Physiol. Anim. Nutr. (Berl.) 97:238-244.

Weisberg, S. P., D. McCann, M. Desai, M. Rosenbaum, R. L. Leibel, and A. W. Ferrante. 2003. Obesity is associated with macrophage accumulation in adipose tissue. J. Clin. Invest. 112:1796-1808.

Wittek, T., M. Fürll, and P. D. Constable. 2004. Prevalence of endotoxemia in healthy postparturient dairy cows and cows with abomasal volvulus or left displaced abomasum. J. Vet. Intern. Med. 18:574-580.

Yadav, D., and A. B. Lowenfels. 2013. The epidemiology of pancreatitis and pancreatic cancer. Gastroenterology 144:1252-1261.

Zachut, M., H. Honig, S. Striem, Y. Zick, S. Boura-Halfon, and U. Moallem. 2013. Periparturient dairy cows do not exhibit hepatic insulin resistance, yet adipose-specific insulin resistance occurs in cows prone to high weight loss. J. Dairy Sci. 96:5656-5669. 